\title{
Asymmetric conjugate addition of bromonitromethane to cyclic enones catalyzed by chiral monosulfonated diamines
}

\author{
Quan-sheng Du, Li-ting Dong, Jin-jia Wang, Rui-jiong Lu, and Ming Yan* \\ Institute of Drug Synthesis and Pharmaceutical Process, School of Pharmaceutical Sciences, \\ Sun Yat-sen University, Guangzhou 510006, China \\ E-mail:yanming@mail.sysu.edu.cn
}

\begin{abstract}
A series of chiral monosulfonated diamines were prepared and used as the catalysts for asymmetric conjugate addition of bromonitromethane to $\alpha, \beta$-unsaturated ketones. The reaction provided nitrocyclopropanes in the presence of appropriate acid and base additives. 1,3,5-Triisopropylbenzenesulfonated 1,2-diphenylethane-1,2-diamine was found to be the best catalyst. The reaction of cyclohex-2-enone and cyclohept-2-enone gave the nitrocyclopropanes in excellent enantioselectivities and yields. Moderate enantioselectivities were obtained for cyclopent-2-enone. The hydrogen-bonding interaction between $\mathrm{N}-\mathrm{H}$ bonds of sulfonamides and bromonitromethane is suggested to be important for the catalytic activity and enantioselectivity.
\end{abstract}

Keywords: Asymmetric conjugate addition, organocatalysis, bromonitromethane, $\alpha, \beta$-unsaturated ketone, nitrocyclopropane

\section{Introduction}

In the past decade, significant progress has been achieved in asymmetric reactions catalyzed by chiral small organic molecules. ${ }^{1}$ Among a large number of organocatalysts developed so far, chiral bifunctional catalysts combining hydrogen-bond donors and amines are extremely efficient for many asymmetric transformations. ${ }^{2}$ Thioureas, ureas, guanidiums and trifluoromethanesulfonamides have been the most used hydrogen-bond donators. Recently we found that sulfamides are also efficient hydrogen-bond donors. ${ }^{3}$ In a study of the effect of hydrogen-bond donors on the catalytic activity and enantioselectivity of bifunctional primary amine catalysts, we noticed that the catalytic activity is not proportional to the $\mathrm{N}-\mathrm{H}$ acidity or generally related with the hydrogen-bonding interaction modes. Monosulfonated cyclohexane-1,2-diamine, which possesses a weakly acidic N-H bond, is able to provide efficient 
hydrogen-bonding interaction for the conjugate addition of carbonyl compounds to nitroalkenes. ${ }^{4}$ Chiral sulfonamides were also reported to be efficient catalysts for several other reactions. ${ }^{5}$ Very recently, we found that thiourea-amines derived from 1,2-diphenylethanediamine are highly efficient catalysts for the conjugate addition of bromonitromethane to cyclic enones. ${ }^{6,7}$ The reaction provided valuable nitrocyclopropanes in excellent yields and enantioselectivities. A bifunctional catalytic mechanism was suggested. As an interesting comparison, a series of monosulfonated 1,2-diphenylethanediamines was prepared and examined as the catalysts for this reaction. ${ }^{8}$ The results are reported in this paper.

\section{Results and Discussion}

Chiral monosulfonated diamines 1a - 1f were prepared (Scheme 1) and examined as the catalysts for the reaction of cyclohex-2-enone $\mathbf{2 a}$ and bromonitromethane $\mathbf{3}$. The results are summarized in Table 1. The nitrocyclopropane 4a was obtained in the presence of benzoic acid and $N$-methylmorpholine (NMM). $p$-Toluenesulfonated 1,2-diphenylethane-1,2-diamine 1a provided 4a in good yield and enantioselectivity (Table 1, entry 1). p-Chlorobenzenesulfonated 1,2-diphenylethane-1,2-diamine $\mathbf{1 b}$ gave a similar yield and enantioselectivity (Table 1, entry 2). The introduction of a strongly electron-withdrawing trifluoromethyl group 1c resulted in a better yield and enantioselectivity (Table 1, entry 3). The use of the sterically demanding 1,3,5-trimethylbenzenesulfonyl group 1d also improved the enantioselectivity (Table 1, entry 4). Further increase of the volume of the sulfonyl group led to catalyst 1e, which provided $\mathbf{4 a}$ in excellent yield and enantioselectivity (Table 1, entry 5). For comparison, 1,3,5-triisopropylbenzenesulfonated cyclohexane-1,2-diamine (1f) was prepared and examined in the reaction. Only low enantioselectivity was obtained. The result implies that the structure of the 1,2-diamine influences the enantioselectivity significantly.

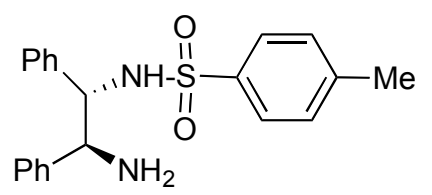

$1 \mathrm{a}$

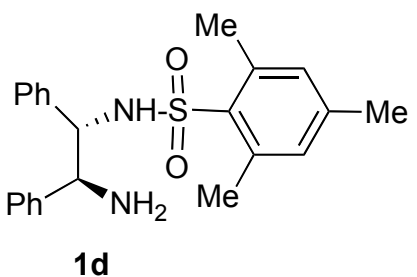

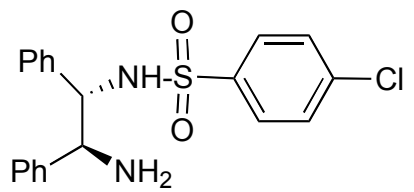

$1 \mathrm{~b}$

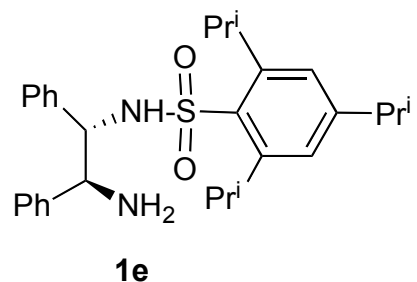

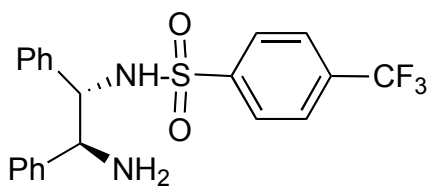

1c

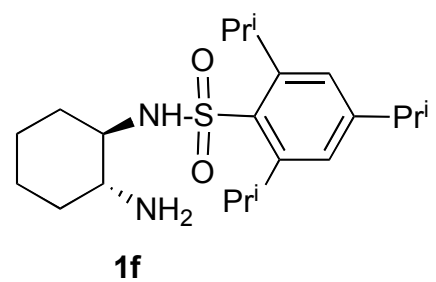

Scheme 1 
Table 1 . The reaction of cyclohex-2-enone $\mathbf{2 a}$ and bromonitromethane $\mathbf{3}$ catalyzed by $\mathbf{1 a - 1 \mathbf { f } ^ { \mathrm { a } }}$

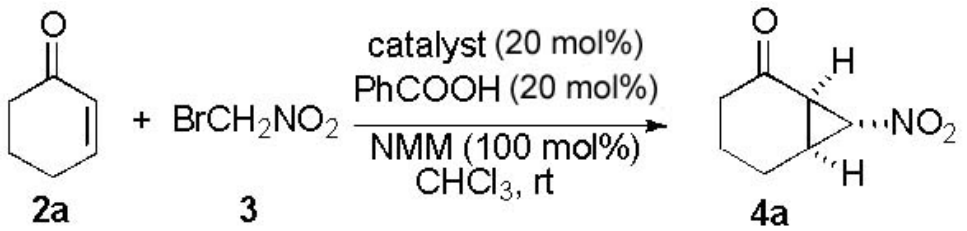

\begin{tabular}{ccccc}
\hline Entry & Catalyst & Time $(\mathrm{h})$ & Yield (\%) $^{\mathrm{b}}$ & Ee (\%) ${ }^{\text {c,d }}$ \\
\hline 1 & $\mathbf{1 a}$ & 16 & 83 & 84 \\
2 & $\mathbf{1 b}$ & 16 & 85 & 84 \\
3 & $\mathbf{1 c}$ & 16 & 86 & 90 \\
4 & $\mathbf{1 d}$ & 16 & 85 & 90 \\
5 & $\mathbf{1 e}$ & 18 & 96 & 92 \\
6 & $\mathbf{1 f}$ & 28 & 80 & -55 \\
\hline
\end{tabular}

${ }^{a}$ Reaction conditions: $\mathbf{2 a}(0.3 \mathrm{mmol}), \mathbf{3}(0.25 \mathrm{mmol}), \mathbf{1 a}-\mathbf{1 f}(0.05 \mathrm{mmol}), \mathrm{PhCOOH}(0.05 \mathrm{mmol})$ and NMM $(0.25 \mathrm{mmol})$ in $\mathrm{CHCl}_{3}(0.5 \mathrm{~mL})$; ${ }^{\mathrm{b}}$ Isolated yields; ${ }^{\mathrm{c}}$ Determined by chiral HPLC analysis ; ${ }^{\mathrm{d}}$ The absolute configuration of the product was determined to be $(1 R, 6 S, 7 R)$ for the catalysts 1a-1e, and $(1 S, 6 R, 7 S)$ for $\mathbf{1 f}$ by comparing the optical rotations with the reported values. $^{7 \mathrm{~b}, 7 \mathrm{c}}$

Although the exact catalytic mechanism is not clear at the present, the hydrogen-bonding interaction between weakly acidic N-H bonds of sulfonamides and 1-bromonitromethane is suggested to be important for the catalytic activity and enantioselectivity (Scheme 2). ${ }^{6}$

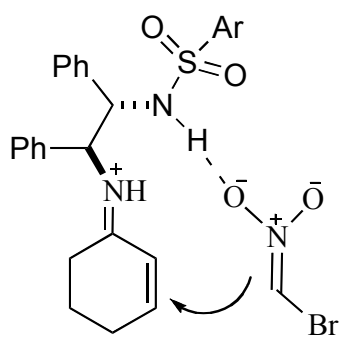

Scheme 2

A number of reaction solvents was screened using $1 \mathbf{e}$ as the catalyst and the results are summarized in Table 2. Less polar solvents, such as $\mathrm{CH}_{2} \mathrm{Cl}_{2}$, toluene, $\mathrm{Et}_{2} \mathrm{O}$ and THF provided $4 \mathbf{a}$ in good yields and enantioselectivities (Table 2, entries 1-6). A mixed solvent, toluene $/ \mathrm{CH}_{2} \mathrm{Cl}_{2}(V / V=$ $7 / 3$ ), was identified as the best solvent in terms of enantioselectivity and yield (Table 2, entry 4). Wang and co-workers firstly used this solvent in the same reaction catalyzed by 9-amino-9-deoxyepiquinine and observed the enhanced effects. ${ }^{7 \mathrm{c}}$ Polar solvents seemed to be detrimental to the reaction. Lower enantioselectivity and yield were observed in $\mathrm{MeOH}$ (Table 2, 
entry 7). No reaction occurred in DMSO (Table 2, entry 8). The reaction in water gave almost racemic 4a in low yield (Table 2, entry 9). The less efficient hydrogen-bonding interactions were expected in these polar solvents.

Table 2. The effect of reaction solvents ${ }^{\mathrm{a}}$

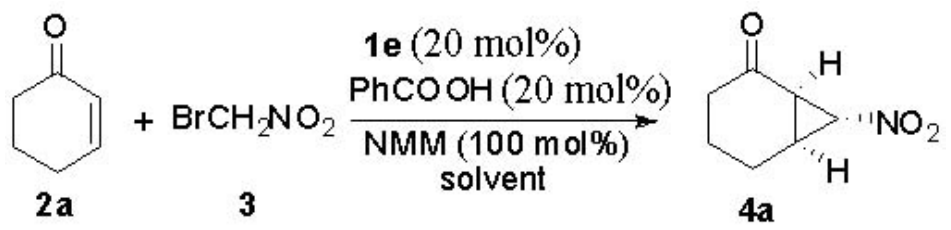

\begin{tabular}{ccccc}
\hline Entry & Solvent & Time $(\mathrm{h})$ & Yield $(\%)$ & Ee $(\%)$ \\
\hline 1 & $\mathrm{CHCl}_{3}$ & 18 & 96 & 92 \\
2 & $\mathrm{CH}_{2} \mathrm{Cl}_{2}$ & 12 & 87 & 90 \\
3 & Toluene & 16 & 85 & 95 \\
4 & Toluene/ $\mathrm{CH}_{2} \mathrm{Cl}_{2}$ & 12 & 90 & 95 \\
& $(V / V=7 / 3)$ & & & \\
5 & $\mathrm{THF}$ & 12 & 85 & 94 \\
6 & $\mathrm{Et} \mathrm{H}_{2} \mathrm{O}$ & 12 & 87 & 92 \\
7 & $\mathrm{MeOH}$ & 16 & 70 & 66 \\
8 & $\mathrm{DMSO}$ & - & - & - \\
9 & $\mathrm{H}_{2} \mathrm{O}$ & 12 & 34 & 4 \\
\hline
\end{tabular}

${ }^{\text {a }}$ Reaction conditions: $\mathbf{2 a}(0.3 \mathrm{mmol}), \mathbf{3}(0.25 \mathrm{mmol}), \mathbf{1 e}(0.05 \mathrm{mmol}), \mathrm{PhCOOH}(0.05 \mathrm{mmol})$ and $\mathrm{NMM}(0.25 \mathrm{mmol})$ in solvent $(0.5 \mathrm{~mL})$ at room temperature.

The effect of acid and base additives on the reaction was studied and the results are summarized in Table 3 . The product 4a was obtained in low yield in the absence of acid additives (Table 3, entry 1). Acetic acid, trifluoroacetic acid (TFA), $p$-toluenesulfonic acid ( $p$-TSA) and benzoic acid accelerated the reaction (Table 3, entries 2-5). Benzoic acid was identified as the best acid additive in terms of both enantioselectivity and yield. On the other hand, base additives were also important for the reaction. No product was observed in the absence of base additive (Table 3 , entry 6). $\mathrm{Et}_{3} \mathrm{~N}, \mathrm{DABCO}$, DMAP and morpholine gave 4a in low yields (Table 3, entries 7-10). Imidazole and pyridine provided better yields (Table 3, entries 11-12). NMM was the most efficient base additive. Good yield and excellent enantioselectivity were achieved (Table 3, entry 5). 
Table 3. The effect of the acid and base additives ${ }^{\mathrm{a}}$

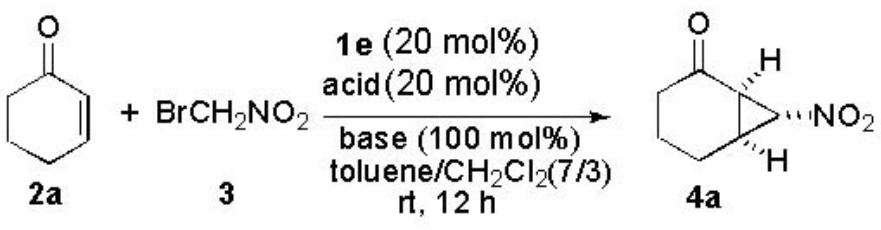

\begin{tabular}{ccccc}
\hline Entry & Acid & Base & Yield $(\%)$ & Ee $(\%)$ \\
\hline 1 & - & NMM & 60 & 90 \\
2 & AcOH & NMM & 82 & 95 \\
3 & TFA & NMM & 85 & 91 \\
4 & $p$-TSA & NMM & 70 & 91 \\
5 & PhCOOH & NMM & 90 & 95 \\
6 & PhCOOH & - & 0 & - \\
7 & PhCOOH & Et $_{3} N$ & 39 & 59 \\
8 & PhCOOH & DABCO & 28 & 92 \\
9 & PhCOOH & DMAP & 39 & 84 \\
10 & PhCOOH & Morpholine & 54 & 60 \\
11 & PhCOOH & Imidazole & 70 & 93 \\
12 & PhCOOH & Pyridine & 72 & 90 \\
\hline
\end{tabular}

${ }^{\mathrm{a}}$ Reaction conditions: $\mathbf{2 a}(0.3 \mathrm{mmol}), \mathbf{3}(0.25 \mathrm{mmol}), \mathbf{1 e}(0.05 \mathrm{mmol})$, acid additive $(0.05 \mathrm{mmol})$ and base additive $(0.25 \mathrm{mmol})$ in toluene $/ \mathrm{Et}_{2} \mathrm{O}(7 / 3)(0.5 \mathrm{~mL})$ at room temperature for $12 \mathrm{~h}$.

A number of cyclic enones were examined and the results are summarized in Table 4. Excellent enantioselectivities and yields were obtained for cyclohex-2-enone, 4,4-dimethyl-cyclohex-2-enone, and 3-methyl-cyclohex-2-enone (Table 4, entries 1-3). However 5,5,3-trimethyl-cyclohex-2-enone was unreactive, probably due to its substantial steric hindrance (Table 4, entry 4). Excellent enantioselectivity was also obtained for cyclohept-2-enone (Table 4, entry 5), however only moderate enantioselectivity was achieved for cyclopent-2-enone (Table 4, entry 6). Acyclic enones, such as chalcone and benzylideneacetone, did not react with 1-bromonitromethane under the present reaction conditions. 
Table 4. Reaction of 1-bromonitromethane with cyclic enones catalyzed by $1 \mathrm{e}^{\mathrm{a}}$

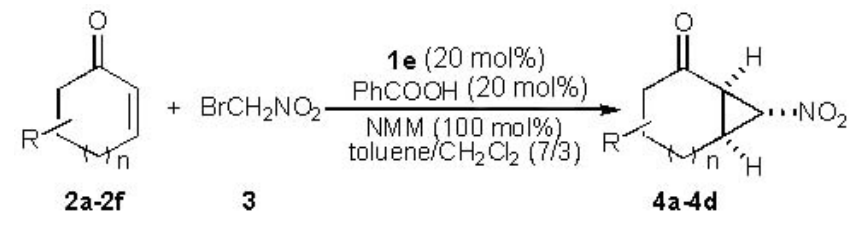

Entry

${ }^{a}$ Reaction conditions: $\mathbf{2 a - 2 f}(0.3 \mathrm{mmol}), 3(0.25 \mathrm{mmol})$, $\mathbf{1 e}(0.05 \mathrm{mmol})$, PhCOOH $(0.05 \mathrm{mmol})$ and NMM $(0.25 \mathrm{mmol})$ in toluene/ $\mathrm{CH}_{2} \mathrm{Cl}_{2}(7 / 3)(0.5 \mathrm{~mL})$ at room temperature; ${ }^{\mathrm{b}}$ Isolated yields; ${ }^{\mathrm{c}}$ Determined by chiral HPLC analysis. 


\section{Conclusions}

In conclusion we have found that readily available monosulfonated diamines are efficient catalysts for the conjugate addition of bromonitromethane to cyclic enones. Excellent enantioselectivities and yields were achieved for cyclohex-2-enone and cyclohept-2-enone. Moderate enantioselectivities were obtained for cyclopent-2-enone. The results suggest that even weakly acidic N-H bonds of sulfonamides are also available for the bifunctional organocatalysis involving hydrogen-bonding interactions.

\section{Experimental Section}

General. ${ }^{1} \mathrm{H}$ NMR and ${ }^{13} \mathrm{C}$ NMR spectra were recorded on Bruker AVANCE 400 spectrometer. Chemical shifts of protons are reported in parts per million downfield from tetramethylsilane $(\delta=$ $0)$. Chemical shifts of carbon are referenced to the carbon resonances of the solvent $\left(\mathrm{CHCl}_{3}: \delta=\right.$ 77.0). Peaks are labeled as singlet (s), doublet (d), triplet (t), quartet (q) and multiplet (m). Optical rotations were measured on a Perkin-Elmer digital polarimeter. Melting points were measured on a WRS-2A melting point apparatus and are uncorrected. The mass spectroscopic data were obtained at the Thermo DSQII mass spectrometer. Enantiomeric excesses were determined by HPLC using a Daicel Chiralpak AD-H, OD-H, column and eluting with a $n$-hexane $/ i-\mathrm{PrOH}$ solution. Flash chromatography was performed over silica gel (230-400 mesh), purchased from Qingdao Haiyang Chemical Co., Ltd. Commercial reagents were used as received.

\section{Typical procedure for the conjugate addition of bromonitromethane to cyclic enones} Catalyst 1e (24 mg, $0.05 \mathrm{mmol}), \mathrm{PhCOOH}(6 \mathrm{mg}, 0.05 \mathrm{mmol})$ and cyclohex-2-enone $2 \mathrm{a}(29 \mathrm{mg}$, $0.3 \mathrm{mmol})$ were dissolved in toluene/ $\mathrm{CH}_{2} \mathrm{Cl}_{2}(V / V=7 / 3,0.5 \mathrm{~mL})$. The solution was stirred at room temperature for 15 minutes. Then NMM ( $25 \mathrm{mg}, 0.25 \mathrm{mmol}$ ) and bromonitromethane 3 (35 $\mathrm{mg}, 0.25 \mathrm{mmol}$ ) were added and the reaction mixture was stirred at room temperature for $12 \mathrm{~h}$. The reaction solution was diluted with $\mathrm{CH}_{2} \mathrm{Cl}_{2}(5 \mathrm{~mL})$ and washed with aqueous saturated $\mathrm{NaHCO}_{3}(3 \mathrm{~mL})$. The organic layer was separated and dried over anhydrous sodium sulfate. After the solvent was evaporated under vacuum, the residue was purified by flash column chromatography over silica gel (EtOAc/petroleum ether) to provide nitrocyclopropane 4a as a white solid.

(1R,6S,7R)-7-Nitro-bicyclo[4.1.0]heptan-2-one (4a). White solid (90\% yield), $[\alpha]_{20}^{589}=-56.0(\mathrm{c}$ $\left.0.5, \mathrm{CH}_{2} \mathrm{Cl}_{2}\right) .{ }^{1} \mathrm{H}$ NMR $\left(400 \mathrm{MHz}, \mathrm{CDCl}_{3}\right): \delta 4.67(\mathrm{t}, J=2.8 \mathrm{~Hz}, 1 \mathrm{H}), 2.83(\mathrm{dd}, J=9.6,2.7 \mathrm{~Hz}$, 
$1 \mathrm{H}), 2.70-2.65(\mathrm{~m}, 1 \mathrm{H}), 2.38-2.31(\mathrm{~m}, 1 \mathrm{H}), 2.21-2.12(\mathrm{~m}, 2 \mathrm{H}), 2.04-1.95(\mathrm{~m}, 1 \mathrm{H}), 1.91-1.83(\mathrm{~m}$, $1 \mathrm{H}), 1.60-1.48(\mathrm{~m}, 1 \mathrm{H}) ;{ }^{13} \mathrm{C}$ NMR $\left(100 \mathrm{MHz}, \mathrm{CDCl}_{3}\right): \delta 201.1,60.5,37.2,35.2,26.8,19.6,18.2$; MS (EI): $155\left(\mathrm{M}^{+}\right)$. The enantiomeric excess was determined by HPLC with an AD-H column $(n$-hexane $/ i-\mathrm{PrOH}=95 / 5, \lambda=208 \mathrm{~nm}, 0.8 \mathrm{~mL} / \mathrm{min}) ; \mathrm{t}_{\mathrm{R}}($ major $)=22.7 \mathrm{~min}, \mathrm{t}_{\mathrm{R}}(\operatorname{minor})=25.2 \mathrm{~min}$, $95 \%$ ee.

(1R,6S,7R)-7-Nitro-5,5-dimethyl-bicyclo [4.1.0]heptan-2-one (4b). White solid (95\% yield), $[\alpha]_{20}^{899}=-87.4\left(c 0.5, \mathrm{CH}_{2} \mathrm{Cl}_{2}\right) .{ }^{1} \mathrm{H}$ NMR $\left(400 \mathrm{MHz}, \mathrm{CDCl}_{3}\right): \delta 4.66(\mathrm{t}, J=3.2 \mathrm{~Hz}, 1 \mathrm{H}), 2.85(\mathrm{dd}, J=$ 9.6, 7.2 Hz, 1H), 2.44-2.40 (m, 1H), 2.30- $2.27(\mathrm{~m}, 2 \mathrm{H}), 1.57-1.41(\mathrm{~m}, 2 \mathrm{H}), 1.23(\mathrm{~s}, 3 \mathrm{H}), 1.21(\mathrm{~s}$, $3 \mathrm{H}) ;{ }^{13} \mathrm{C}$ NMR $\left(100 \mathrm{MHz}, \mathrm{CDCl}_{3}\right): \delta 201.4,60.1,38.2,36.1,33.3,30.8,29.1,27.9,26.2$; MS (EI): $183\left(\mathrm{M}^{+}\right)$. The enantiomeric excess was determined by HPLC with an AD-H column $(n$-hexane $/ i-\mathrm{PrOH}=98 / 2, \lambda=208 \mathrm{~nm}, 0.8 \mathrm{~mL} / \mathrm{min}) ; \mathrm{t}_{\mathrm{R}}($ minor $)=20.2 \mathrm{~min}, \mathrm{t}_{\mathrm{R}}($ major $)=22.7 \mathrm{~min}$, $94 \%$ ee.

(1R,6S,7R)-7-Nitro-6-methyl-bicyclo[4.1.0]heptan-2-one (4c). Colorless oil (90\% yield), $[\alpha]_{20}^{589}=+44.0\left(\mathrm{c} 0.5, \mathrm{CH}_{2} \mathrm{Cl}_{2}\right) .{ }^{1} \mathrm{H}$ NMR $\left(400 \mathrm{MHz}, \mathrm{CDCl}_{3}\right): \delta 4.79(\mathrm{~d}, J=3.2 \mathrm{~Hz}, 1 \mathrm{H}), 2.89(\mathrm{~d}, J=$ 3.6 Hz, $1 \mathrm{H}), 2.40-2.34(\mathrm{~m}, 1 \mathrm{H}), 2.25-2.19(\mathrm{~m}, 1 \mathrm{H}), 2.13-2.04(\mathrm{~m}, 1 \mathrm{H}), 1.91-1.80(\mathrm{~m}, 2 \mathrm{H})$, 1.60-1.50 (m, 1H), $1.42(\mathrm{~s}, 3 \mathrm{H}) ;{ }^{13} \mathrm{C}$ NMR (100 MHz, $\left.\mathrm{CDCl}_{3}\right): \delta 202.0,65.4,40.4,36.4,32.6$, 28.4, 17.5, 17.4; MS (EI): $169\left(\mathrm{M}^{+}\right)$. The enantiomeric excess was determined by HPLC with an AD-H column $(n$-hexane $/ i-\mathrm{PrOH}=95 / 5, \lambda=208 \mathrm{~nm}, 0.8 \mathrm{~mL} / \mathrm{min}) ; \mathrm{t}_{\mathrm{R}}$ (major) $=14.2 \mathrm{~min}, \mathrm{t}_{\mathrm{R}}$ $($ minor $)=17.1 \mathrm{~min}, 94 \%$ ee

$(1 R, 7 S, 8 R)$-8-Nitro-bicyclo[5.1.0]octan-2-one (4e). Colorless oil (87\% yield), $[\alpha]_{20}^{889}=-24.9$ (c 0.5, $\left.\mathrm{CH}_{2} \mathrm{Cl}_{2}\right) .{ }^{1} \mathrm{H}$ NMR $\left(400 \mathrm{MHz}, \mathrm{CDCl}_{3}\right): \delta 4.63(\mathrm{t}, J=3.6 \mathrm{~Hz}, 1 \mathrm{H}), 3.12(\mathrm{dd}, J=12.0,3.6 \mathrm{~Hz}$, $1 \mathrm{H}), 2.65-2.58(\mathrm{~m}, 1 \mathrm{H}), 2.46-2.38(\mathrm{~m}, 2 \mathrm{H}), 2.23-2.16(\mathrm{~m}, 1 \mathrm{H}), 1.73-1.30(\mathrm{~m}, 5 \mathrm{H}) ;{ }^{13} \mathrm{C}$ NMR $(100$ $\left.\mathrm{MHz}, \mathrm{CDCl}_{3}\right): \delta 203.3,62.9,43.1,39.9,27.3,26.9,25.6,24.4$; MS (EI): $169\left(\mathrm{M}^{+}\right)$. The enantiomeric excess was determined by HPLC with an AD-H column ( $n$-hexane $/ i$-PrOH $=98 / 2, \lambda$ $=208 \mathrm{~nm}, 0.8 \mathrm{~mL} / \mathrm{min}) ; \mathrm{t}_{\mathrm{R}}($ major $)=19.9 \mathrm{~min}, \mathrm{t}_{\mathrm{R}}($ minor $)=21.2 \mathrm{~min}, 96 \%$ ee.

$(1 R, 5 S, 6 R)$-6-Nitro-bicyclo[3.1.0]hexan-2-one (4f). Light yellow solid (70\% yield), $[\alpha]_{20}^{89}=$ $+11.2\left(\mathrm{c} 0.5, \mathrm{CH}_{2} \mathrm{Cl}_{2}\right) .{ }^{1} \mathrm{H} \mathrm{NMR}\left(400 \mathrm{MHz}, \mathrm{CDCl}_{3}\right): \delta 4.41(\mathrm{t}, J=2.0 \mathrm{~Hz}, 1 \mathrm{H}), 3.01-2.97(\mathrm{~m}, 1 \mathrm{H})$, $2.82(\mathrm{~d}, J=6.8 \mathrm{~Hz}, 1 \mathrm{H}), 2.41-2.20(\mathrm{~m}, 3 \mathrm{H}), 2.02-1.93(\mathrm{~m}, 1 \mathrm{H}) ;{ }^{13} \mathrm{C}$ NMR $(100 \mathrm{MHz}, \mathrm{CDCl} 3): \delta$ 207.6, 61.8, 37.5, 32.4, 30.8, 22.0; MS (EI): $141\left(\mathrm{M}^{+}\right)$. The enantiomeric excess was determined by HPLC with an AD-H column ( $n$-hexane $/ i-\mathrm{PrOH}=95 / 5, \lambda=208 \mathrm{~nm}, 0.7 \mathrm{~mL} / \mathrm{min}) ; \mathrm{t}_{\mathrm{R}}$ (major) $=$ $29.8 \mathrm{~min}, \mathrm{t}_{\mathrm{R}}($ minor $)=31.1 \mathrm{~min}, 63 \%$ ee. 


\section{Acknowledgments}

We thank National Natural Science Foundation of China (No. 20772160, 20972195), Zhuhai Bureau of Science and Technology for the financial support of this study.

\section{References}

1. For the general reviews of asymmetric organocatalysis, see: (a) Dondoni, A.; Massi, A. Angew. Chem. Int. Ed. 2008, 47, 4638. (b) Yu, X. H.; Wang, W. Chem. Asian J. 2008, 3, 516. (c) MacMillan, D. W. C. Nature 2008, 455, 304. (d) Dalko, P. I. Enantioselective Organocatalysis, Wiley-VCH, Weinheim, 2007.

2. For the reviews of bifunctional organocatalysts, see: (a) Connon, S. J. Chem. Eur. J. 2006, 12, 5418. (b) Taylor, M. S.; Jacobsen, E. N. Angew. Chem. Int. Ed. 2006, 45, 1520.

3. (a) Zhang, X. J.; Liu, S. P.; Li, X. M.; Yan, M.; Chan, A. S. C. Chem.Commun. 2009, 833. (b) Liu, S. P.; Zhang, X. J.; Lao, J. H.; Yan, M. Arkivoc 2009, 7, 268.

4. Lao, J. H.; Zhang, X. J.; Wang, J. J.; Li, X. M.; Yan, M.; Luo, H. B. Tetrahedron: Asymmetry 2010, 21, 2818.

5. For the application of chiral sulfonamides as the organocatalysts, see: (a) Rasappan, R.; Reiser, O. Eur. J. Org. Chem. 2009, 1305. (b) Xue, F.; Zhang, S. L.; Duan, W. H.; Wang, W. Adv. Synth. Catal. 2008, 350, 2194. (c) Wang,W.; Li, H.; Wang, J. Tetrahedron Lett. 2005, 46, 5077. (d) Wang, W.; Wang, J.; Li, H.; Liao, L. X. Tetrahedron Lett. 2004, 45, 7235.

6. Dong, L. T.; Du, Q. S.; Lou, C. L.; Zhang, J. M.; Lu, R. J.; Yan, M. Synlett 2010, 266.

7. For other publications of organocatalytic conjugate addition of bromonitroalkanes to $\alpha, \beta$-unsaturated ketones, see: (a) Hansen, H. M.; Longbottom, D. A.; Ley, S. V. Chem. Commun. 2006, 4838. (b) Wascholowski, V.; Hansen, H. M.; Longbottom, D. A.; Ley, S. V. Synthesis 2008, 1269. (c) Lv, J.; Zhang, J. M.; Lin, Z.; Wang, Y. M. Chem. Eur. J. 2009, 15, 972. (d) Dong, L. T.; Lu, R. J.; Du, Q. S.; Zhang, J. M.; Liu, S. P.; Xuan, Y. N.; Yan, M. Tetrahedron 2009, 65, 4124.

8. For the reviews of monosulfonated diamines as chiral ligands in asymmetric catalysis, see: (a) Ikariya, T.; Blacker, J. Acc. Chem. Res. 2007, 40, 1300. (b) Wang, C.; Wu, X. F.; Xiao, J. L. Chem. Asian J. 2008, 3, 1750. 